\title{
Expansion of Injected Gas Bubble and Its Effects on Bath Mixing under Reduced Pressure
}

\author{
Teruhisa TATSUOKA, Chizuna KAMATA ${ }^{11}$ and Kimihisa ITO ${ }^{21}$
}

Formerly Graduate Student, Department of Materials Science and Engineering, Waseda University, Ohkubo, Shinjuku-ku, Tokyo, 169 Japan. $\quad$ 1) Graduate Student, Department of Materials Science and Engineering, Waseda University, Ohkubo, Shinjuku-ku, Tokyo, 169 Japan. $\quad 2)$ Department of Materials Science and Engineering, Waseda University, Ohkubo, Shinjuku-ku, Tokyo, 169 Japan.E-mail:ki0205/@cfi.waseda.ac.jp

(Received on November 11, 1996; accepted in final form on March 7, 1997)

\begin{abstract}
The behavior of a single bubble was observed and the complete mixing time was measured under reduced pressure $\left(\sim 1.33 \times 10^{2} \mathrm{~Pa}(1 \mathrm{Torr})\right.$ ) using a silicon oil model. The bubble expanded greatly and changed from oval to a spherical-cup shape. The complete mixing time tended to be constant independent of the stirring power of gas per unit bath volume in the low vessel pressure range $\left(<6.66 \times 10^{2} \mathrm{~Pa}\right)$, because most of the expansion energy was dissipated and the mixing occurred near the bath surface; this was confirmed by observation of the flow.
\end{abstract}

KEY WORDS: single bubble; complete mixing time; local stirring power; optical fiber probe; vacuum refining; steelmaking.

\section{Introduction}

Vacuum refining furnaces like the $\mathrm{RH}$ degasser have risen in importance because of the recent need for higher quality steel. There have thus been many several reports on the metallurgical characteristics such as the size and shape of injected bubbles, ${ }^{1-6)}$ mixing characteristics of reactors, ${ }^{7,8)}$ and degassing behavior. ${ }^{9-11)}$ These studies were carried out using either a water model or a molten metal model, and the effects of a liquid's physical properties on the flow parameters were determined for atmospheric pressure operations. The effects of reducing the vessel pressure, however, were discussed in only a few reports. The pressure ranges in these were limited [Iguchi et al. ${ }^{12)}$ used $3 \times 10^{3} \mathrm{~Pa}$, while Sakaguchi and Ito $^{13)}$ used $1.01 \times 10^{5}-2.13 \times 10^{4} \mathrm{~Pa}(760-160$ Torr $)$.] This was due to the experimental difficulties encountered because both used deionized water, which has a vapor pressure of about $3 \times 10^{3} \mathrm{~Pa}$ at $25^{\circ} \mathrm{C}$, as a bath liquid. Since the vessel pressure in a practical refining process is about 1 Torr $\left(1.3 \times 10^{2} \mathrm{~Pa}\right)$, complete simulation is difficult using a water model.

In this study, the vessel pressure was reduced as low as the practical processes because silicon oil with low vapor pressure was used as the bath liquid. The effect of reduced pressure on the bubbles is discussed based on observation of a rinsing single bubble and measurement of the complete mixing time which has been described using the stirring power of gas per unit bath volume. Since the work accompanied by the expansion of the rising bubble is a source of stirring power, the expansion behavior of the bubble should be important. Though the expansion of a group of bubbles must be discussed actually, the observation was limited to that of a single bubble because of experimental difficulties. However, the effects of vessel pressures, hydrostatic pressures and surface tensions on the expansion behavior are expected to be similar. An optical fiber probe was developed to measure the complete mixing time because silicon oil has little electrical conductivity.

\section{Experimental}

The physical properties of silicon oil used as a bath liquid are listed in Table 1. Figure 1 is a schematic drawing of the experimental apparatus used in this study. An acrylic cylinder was filled with silicon oil. The size and depth of the bath are listed in Table 2. To avoid optical distortions, a square vessel made of acrylic resin enclosed the cylindrical vessel and the space between the two vessels was also filled with the same kind of oil. A brass orifice with an inner diameter of $2 \mathrm{~mm}$ was connected with a bulb and a mass flow controller and installed in the center of the bottom of the bath. The vessel pressure

Table 1. Physical properties of bath liquids.

\begin{tabular}{cccccc}
\hline & $\begin{array}{c}\text { tempera- } \\
\text { ture } \\
\text { (deg.) }\end{array}$ & $\begin{array}{c}\text { density } \\
\left(\mathrm{kg} / \mathrm{m}^{3}\right)\end{array}$ & $\begin{array}{c}\text { viscosity } \\
(\mathrm{Pa} \mathrm{s})\end{array}$ & $\begin{array}{c}\text { surface } \\
\text { tension } \\
(\mathrm{N} / \mathrm{m})\end{array}$ & $\begin{array}{c}\text { vapor } \\
\text { pressure } \\
(\mathrm{Pa})\end{array}$ \\
\hline water & 25 & 1000 & $\begin{array}{l}1.00 \\
\times 10^{-3}\end{array}$ & $\begin{array}{c}72 \\
\times 10^{-3}\end{array}$ & $\begin{array}{c}3.17 \\
\times 10^{3}\end{array}$ \\
\hline silicon oil & 25 & 818 & $\begin{array}{c}0.818 \\
\times 10^{-3}\end{array}$ & $\begin{array}{c}16.9 \\
\times 10^{-3}\end{array}$ & $\begin{array}{c}<1.33 \\
\times 10^{2}\end{array}$ \\
\hline molten $\mathrm{Fe}$ & 1600 & 7160 & $\begin{array}{c}6.1 \\
\times 10^{-3}\end{array}$ & 1.7 & 0.112 \\
\hline
\end{tabular}



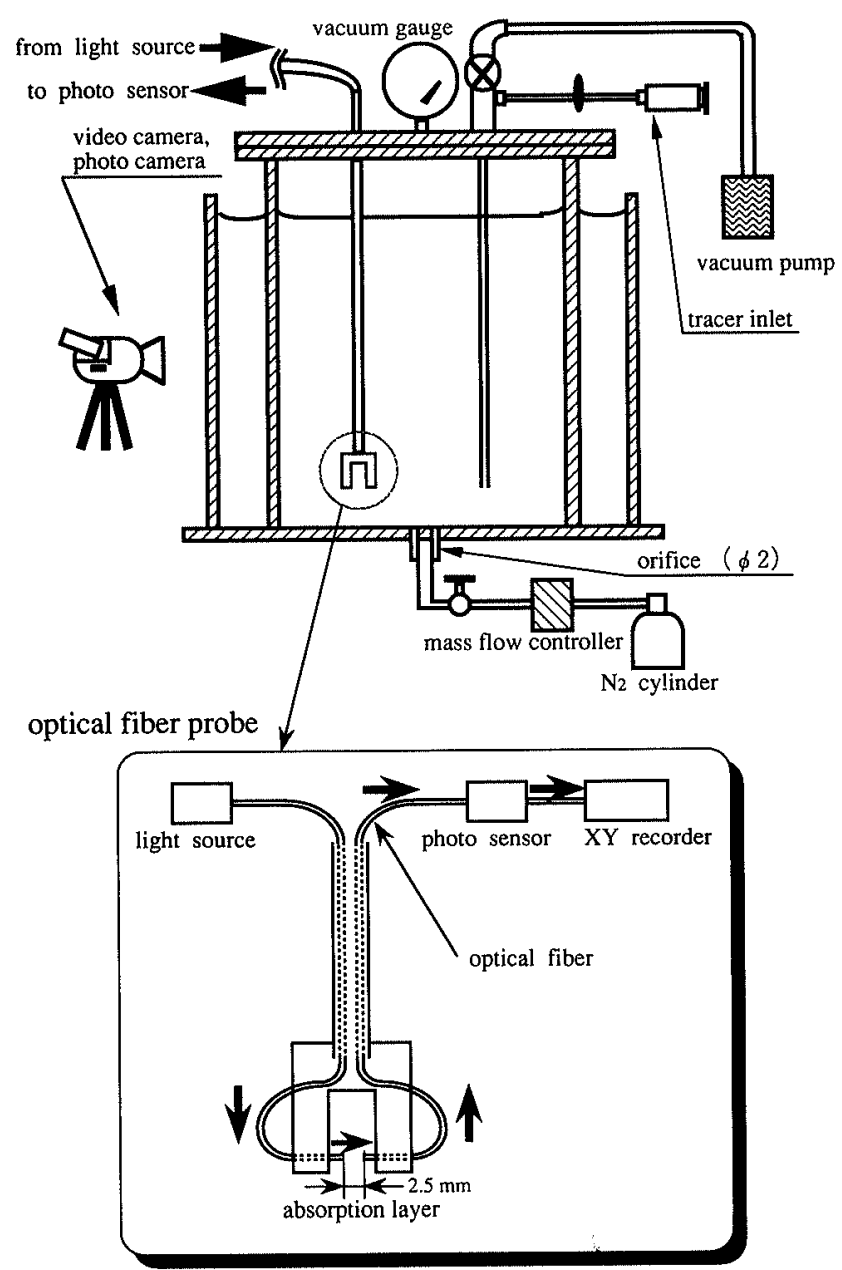

Fig. 1. Schematic drawing of the experimental apparatus.

Table 2. Size and depth of bath.

\begin{tabular}{|c|c|c|c|}
\hline bath No. & $\begin{array}{c}\text { inner } \\
\text { diameter } \\
: D_{0}(\mathrm{~mm})\end{array}$ & $\begin{array}{c}\text { depth : } h_{0} \\
\text { (mm) }\end{array}$ & $h_{0} / D_{b}(-)$ \\
\hline \multirow{3}{*}{1} & \multirow{3}{*}{190} & 100 & 0.5 \\
\hline & & 200 & 1.0 \\
\hline & & 300 & 1.5 \\
\hline \multirow{2}{*}{2} & \multirow{2}{*}{100} & 300 & 3.0 \\
\hline & & 400 & 4.0 \\
\hline
\end{tabular}

was set at the desired value using a vacuum pump and a vacuum gauge installed on top of the cylindrical vessel.

The behavior of a single bubble was observed from the side of the vessel using a photo camera and a video. camera. The vessel pressure was reduced at $1.33 \times 10^{2} \mathrm{~Pa}$ (1 Torr) and the gas flow rate was controlled so that only a single bubble existed in the vessel. Bubble volume was calculated assuming a symmetrical shape.

The complete mixing time under reduced pressure $\left(1.01 \times 10^{5}-2.66 \times 10^{3} \mathrm{~Pa}\right)$ was measured by recording the change in tracer concentration on an $\mathrm{X}-\mathrm{Y}$ recorder after $\mathrm{N}_{2}$ gas was injected at a controlled flow rate $(0.01,0.1$, or $0.5 \mathrm{~N} l / \mathrm{min}$ ), and blue oil ink used as a tracer was injected from the top of the vessel. The complete mixing time is defined as the time required for the change of tracer concentration to be $5 \%$ as much as that injected. The optical fiber probe for measuring the concentration change is shown schematically in Fig. 1; it consists of a

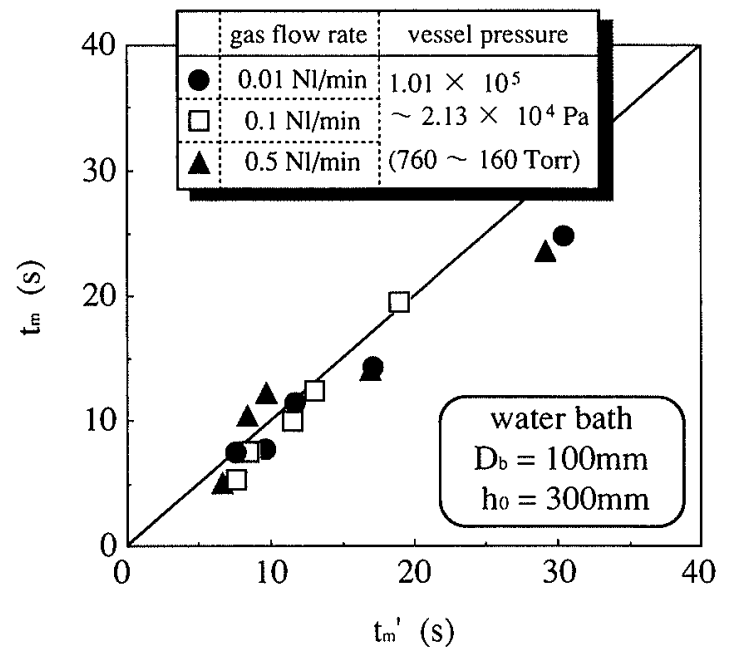

Fig. 2. Comparison of the complete mixing time measured by the optical fiber probe, $t_{\mathrm{m}}$ with that measured by the electrical conductivity probe, $t_{\mathrm{m}}^{\prime}$ in water bath $\left(D_{\mathrm{b}}=\right.$ $100 \mathrm{~mm}, h_{0}=300 \mathrm{~mm}$ )

light source, an absorption layer, and a receiving light. The parts are connected by optical fiber. The absorption layer is $2.5 \mathrm{~mm}$ in width, in which the light transmitted from the light source is absorbed according to the tracer concentration. In the receiving light portion, the change in light intensity was recorded with time. The complete mixing time measured by the optical fiber probe, $t_{\mathrm{m}}$ was compared with that measured by the electrical conductivity probe, $t_{\mathrm{m}}^{\prime}$ using the same water bath (the vessel diameter, $D_{\mathrm{b}}$, was $100 \mathrm{~mm}$ and the depth, $h_{0}$, was $300 \mathrm{~mm}$ ). The vessel pressure was varied $1.01 \times 10^{5}-2.13 \times 10^{4} \mathrm{~Pa}$ (760-160 Torr). An aqueous blue ink was used as a tracer for the optical sensor and $1 \mathrm{~N}$ of $\mathrm{KCl}$ solution was used for the electrical sensor. As shown in Fig. 2, $t_{\mathrm{m}}$ and $t_{\mathrm{m}}^{\prime}$ show good agreements, which would assure the validity of the optical fiber method.

\section{Results and Discussion}

\subsection{Observation of the Behavior of a Single Bubble}

Variation in the diameter, $d$, of the rising bubble's in a water system, a silicon oil system, and a molten iron system is calculated assuming that the spherical bubble isothermally expands in the bath. The results are shown in Fig. 3, where $d_{0}$ is the initial diameter (the diameter at which the distance from the bath surface, $h$, equals $400 \mathrm{~mm})$ and $d / d_{0}$ is adopted as an ordinate. The initial diameter is calculated by Eq. (1), which is derived by assuming static conditions, ${ }^{14,15)}$

$$
d_{0}=\left(\frac{6 \sigma d^{\prime}}{\rho g}\right)^{1 / 3}
$$

where $\sigma$ is the surface tension, $d^{\prime}$ is the orifice diameter, $\rho$ is the liquid density, and $g$ is the gravity acceleration. It is expected from this figure that the bubble diameter changes little under the atmospheric pressure, but the expansion of the bubble is enhanced as the vessel pressure lowers, and the bubble diameter at the bath surface $(h=0 \mathrm{~mm})$ is three or four times larger than the initial one when the vessel pressure is $1.33 \times 10^{3} \mathrm{~Pa}$. Figure 4 is 


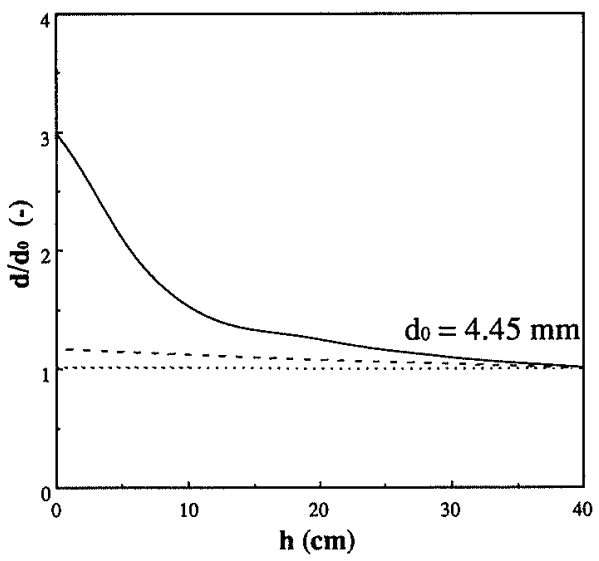

(a) water system

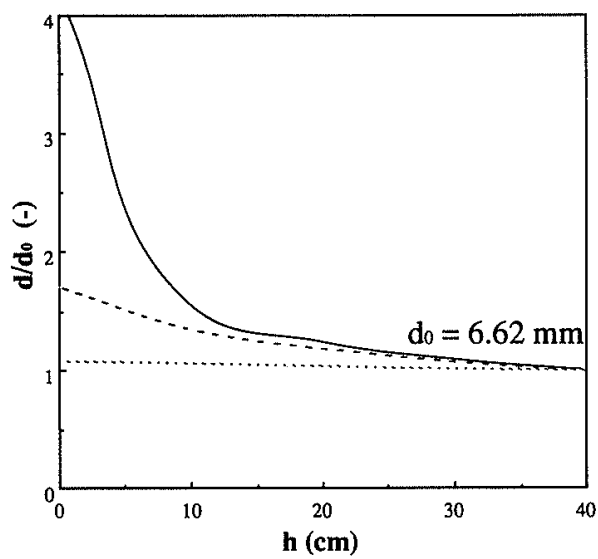

(c) molten $\mathrm{Fe}$ bath

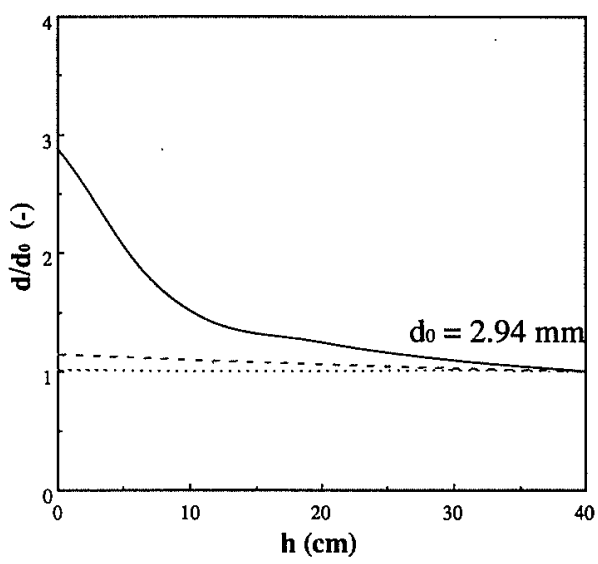

(b) silicon oil bath

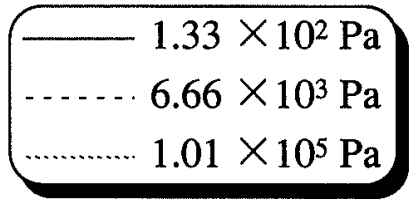

Fig. 3. Variation of $d / d_{0}$ as function of distance from the bath surface, $h$. (calculated)

a photograph of the bubble near the orifice and bath surface. The initial bubble diameter was a little smaller than that calculated by Eq. (1) and the shape was slightly distorted, but it can be seen that the bubble expanded greatly, as expected by the calculation, although, the shape changed from oval to a spherical-cap. Figure 5(a) shows the variation of the bubble's width, $a$, and height, $b$, as a function of the distance from the bath surface, and Fig. 5(b) shows the variation of the sphere equivalent diameter, $d_{\mathrm{c}}$. The expansion is seen to have occurred near the bath surface and the bubble's width is larger than its height. The solid line is the calculated value shown in Fig. 3(b), which shows that the values obtained considering the static conditions agree with the bubble's height.

Grace reported that when Eötvos number, Eo defined by Eq. (2), exceeds 40 , the bubble shape changes from oval to a spherical-cup. ${ }^{16}$

$$
E o=\frac{g d_{\mathrm{e}}^{2} \rho}{\sigma}
$$

Since $E o$ is estimated to exceed 40 around $h=50 \mathrm{~mm}$ by substituting the value of $d_{\mathrm{e}}$ shown in Fig. 5(b) into Eq. (2), which agrees the observation. The observed $d_{\mathrm{e}}$ in the upper part of the silicon bath was 1.5-2 times larger than the value calculated assuming bubble to be spherical because of the shape change. Therefore the shape of bubble in a molten iron can be also expected by calculating Eo.

\subsection{Measurements of the Complete Mixing Time}

Figure 6 shows the relation between the complete mixing time, $t_{\mathrm{m}}$, and the stirring power of gas per unit bath volume, $\dot{\varepsilon}$, defined by Eq. (3) under the vessel pressure, $P_{0}$ of $1.01 \times 10^{5}-2.66 \times 10^{3} \mathrm{~Pa}$.

$$
\dot{\varepsilon}=\frac{\dot{n} R T}{V_{\mathrm{b}}} \ln \left(1+\frac{\rho g h_{0}}{P_{0}}\right)
$$

where $\dot{n}$ is the molar flow rate of injection gas, $R$ is the gas constant, $T$ is the liquid temperature, and $V_{\mathrm{b}}$ is the bath volume. The relation between $t_{\mathrm{m}}$ and $\dot{\varepsilon}$ is usually expressed as shown in Eq. (4),

$$
t_{\mathrm{m}} \propto \dot{\varepsilon}^{-n}
$$

The power, $n$, takes a value of $0.2-0.5$ and depends on the reactor size and the injection method. ${ }^{7,17)}$ But in this study, as shown in Fig. 6, the complete mixing time tended to be constant independent of the stirring power of gas per unit bath volume in the low vessel pressure range $\left(<6.66 \times 10^{2} \mathrm{~Pa}\right)$; this can be explained as follows.

The above-mentioned $\dot{\varepsilon}$ is the mean value of the maximum work that the injection gas can do to the unit volume liquid over the whole bath. As shown in Eq. (5), however, the local stirring power of gas per unit bath 

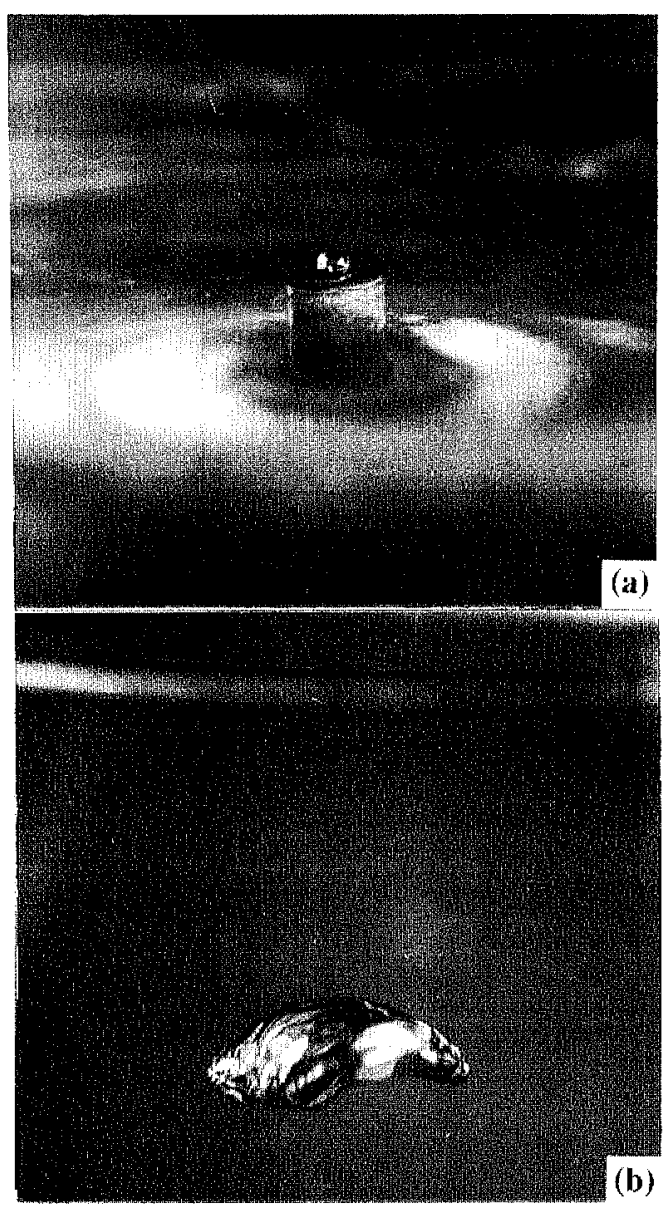

Fig. 4. Photograph of a single bubble in a silicon oil bath under reduced pressure. $\left(P_{0}=1.33 \times 10^{2} \mathrm{~Pa}\right)$

(a) $h=400 \mathrm{~mm}, a=2.7 \mathrm{~mm}, b=2.3 \mathrm{~mm}$

(b) $h=50 \mathrm{~mm}, a=21.4 \mathrm{~mm}, b=5.8 \mathrm{~mm}$.

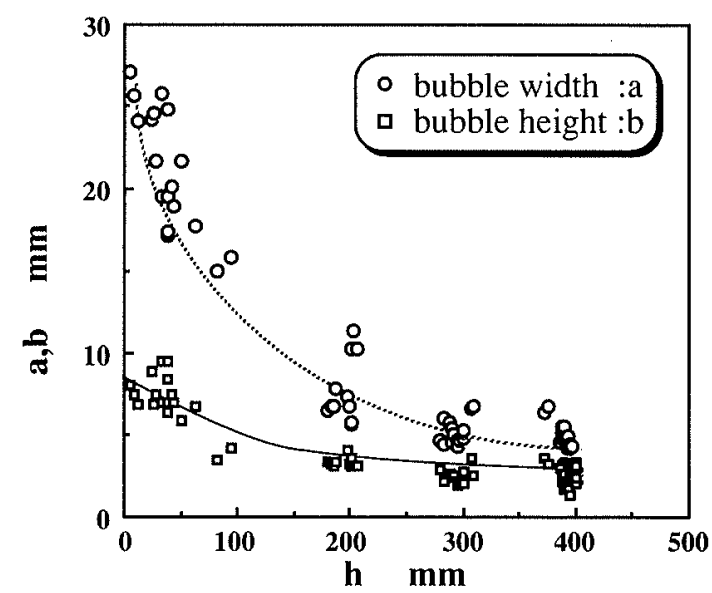

Fig. 5(a). Variation of width of bubble, $a$, and height of bubble, $b$, as a function of distance from the bath surface, $h$. (experiment, $P_{0}=1.33 \times 10^{2} \mathrm{~Pa}$ )

volume at $h, \dot{\varepsilon}_{\text {local }}$, is defined by the work accompanied by the rising bubble from $h$ to $h-\Delta h$,

$$
\begin{aligned}
\dot{\varepsilon}_{\text {local }} & =\lim _{\Delta h \rightarrow 0}\left\{\frac{\dot{n} R T}{A_{\mathrm{b}} \Delta h} \ln \left(\frac{P_{0}+\rho g h}{P_{0}+\rho g(h-\Delta h)}\right)\right\} \\
& =\frac{\dot{n} R T}{A_{\mathrm{b}}} \times \frac{\rho g}{P_{0}+\rho g h} \ldots \ldots \ldots \ldots \ldots \ldots \ldots \ldots \ldots \ldots \ldots \ldots \ldots
\end{aligned}
$$

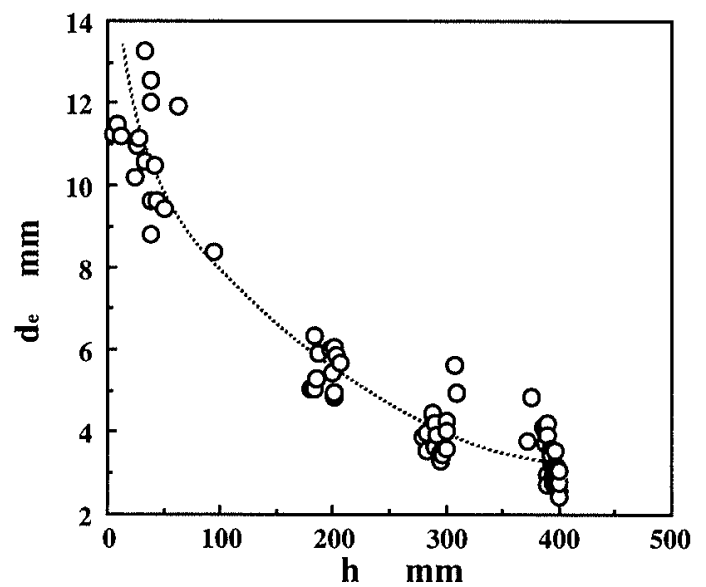

Fig. 5(b). Variation of sphere equivalent diameter, $d_{\mathrm{e}}$, as a function of distance from the bath surface, $h$. (experiment, $P_{0}=1.33 \times 10^{2} \mathrm{~Pa}$ )

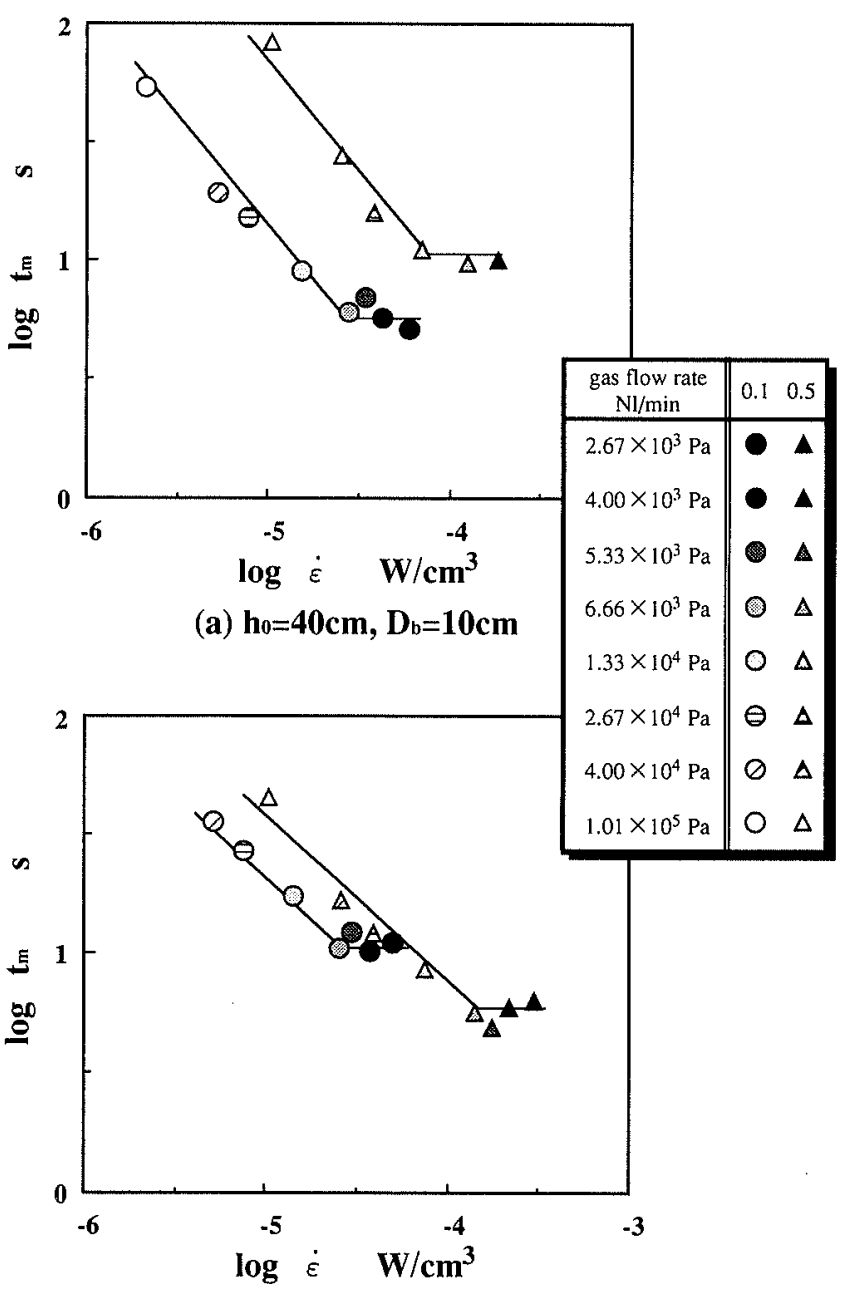

(b) $h_{0}=20 \mathrm{~cm}, D_{b}=10 \mathrm{~cm}$

Fig. 6. Relation between complete mixing time, $t_{\mathrm{m}}$ and the stirring power of gas per unit bath volume, $\dot{\varepsilon}$.

where $A_{\mathrm{b}}$ is the cross sectional area of the bath. The averaged value of this $\dot{\varepsilon}_{\text {local }}$ over the entire bath corresponds to $\dot{\varepsilon}$ as shown in Eq. (6)

$$
\frac{\int_{0}^{h_{\mathrm{o}}} \dot{\varepsilon}_{\text {local }} d h}{\int_{0}^{h_{\mathrm{o}}} d h}=\frac{\frac{\dot{n} R T}{A_{\mathrm{b}}}\left[\ln \left(P_{0}+\rho g h\right)\right]_{0}^{h_{\mathrm{o}}}}{h_{0}}=\dot{\varepsilon}
$$




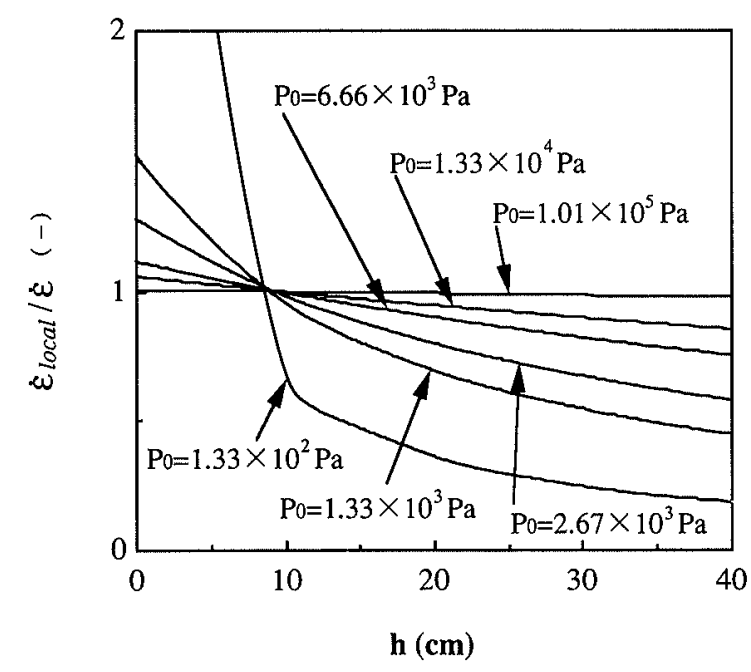

Fig. 7. Variation of $\dot{\varepsilon}_{\text {local }} / \dot{\varepsilon}$ as a function of $h$.

The variation of $\dot{\varepsilon}_{\text {local }} / \dot{\varepsilon}$ as a function of distance from the surface, $h$, is shown in Fig. 7. The $\dot{\varepsilon}_{\text {local }} / \dot{\varepsilon}$ is always near 1 under atmospheric pressure, while it is less than $l$ in the large $h$ region and exceeds $l$ in the small $h$ region under reduced pressure. This tendency becomes stronger with decrease in the vessel pressure; that is to say, the average stirring power becomes greater as the vessel pressure is reduced as shown in Eq. (3), but the large expansion energy is dissipated near the bath surface. Accordingly, mixing throughout the entire bath is hard to maintain and the complete mixing time is limited despite the great stirring power calculated in Eq. (3). It was confirmed by flow observation that the flow pattern changed and mixing of the liquid was maintained primarily near the bath surface as the vessel pressure was reduced. Thus, the use of Eq. (3) to calculate the mixing power under reduced pressure should be done with care because the stirring power of the gas might be overestimated.

\section{Conclusion}

The behavior of a single bubble was observed and the complete mixing time of gas injected was measured under reduced pressure. The major findings were:

(1) A rising single bubble expanded and the shape changed from oval to a spherical-cap shape.

(2) The complete mixing time tended to be constant independent of the stirring power of gas per unit bath volume, $\dot{\varepsilon}$, shown in Eq. (3) in the low vessel pressure range $\left(<6.66 \times 10^{2} \mathrm{~Pa}\right)$. Depending on the local stirring power, $\dot{\varepsilon}_{\text {local }}$, most of the expansion energy is dissipated near the bath surface.

$$
\dot{\varepsilon}=\frac{\dot{n} R T}{V_{\mathrm{b}}} \ln \left(1+\frac{\rho g h_{0}}{P_{0}}\right)
$$

(3) Mixing is believed to occur near the bath surface with the reduction in vessel pressure.

\section{Acknowledgments}

The authors wish to thank Mr. K. Sakaguchi, Mr. M. Sasaki, and Ms. C. Osada for their technical assistance in the preliminary experiments of this work. Part of this study was financially supported by the Iron \& Steel Research Promotion Fund of ISIJ.

\section{Nomenclature}

$a$ : bubble width (L)

$A_{\mathrm{b}}$ : cross sectional area of bath $\left(\mathrm{L}^{2}\right)$

$b$ : bubble height (L)

$d$ : bubble diameter (L)

$d_{\mathrm{e}}:$ sphere equivalent diameter $(\mathrm{L})$

$d_{0}:$ initial bubble diameter (L)

$d^{\prime}:$ orifice diameter (L)

$D_{\mathrm{b}}:$ bath diameter $(\mathrm{L})$

$g$ : gravitational acceleration $\left(\mathrm{L} \mathrm{T}^{-2}\right)$

$h$ : distance from bath surface (L)

$h_{0}$ : bath depth (injection depth) (L)

$\dot{n}$ : molar flow rate of gas injection $\left(\mathrm{T}^{-1} \mathrm{~mol}\right)$

$P_{0}: \quad$ vessel pressure $\left(\mathrm{L}^{-1} \mathrm{M} \mathrm{T}^{-2}\right)$

$R:$ gas constant $\left(\mathrm{L}^{2} \mathrm{M} \mathrm{T}^{-2} \mathrm{~mol}^{-1} \mathrm{~K}^{-1}\right)$

$t_{\mathrm{m}}:$ complete mixing time $(\mathrm{T})$

$T:$ liquid temperature $(\mathrm{K})$

$V_{\mathrm{b}}$ : bath volume $\left(\mathrm{L}^{3}\right)$

$\dot{\varepsilon}$ : stirring power of gas per unit bath volume $\left(\mathrm{M} \mathrm{T}^{-3}\right)$

$\dot{\varepsilon}_{\text {local }}$ : local stirring power of gas per unit bath volume $\left(\mathrm{M} \mathrm{T}^{-3}\right)$

$\rho:$ density $\left(\mathrm{L}^{-3} \mathrm{M}\right)$

$\sigma:$ surface tension $\left(\mathrm{M} \mathrm{T}^{-2}\right)$

\section{REFERENCES}

1) R. M. Davies, D. H. Napier and D. M. Newitt: Trans. Inst. Chem. Eng. (London), 75 (1951), 29.

2) W. Siemes: Chemie. Ing. Tech., 26 (1954), 479; 614; Chem. Eng., $38(1960), 127$.

3) L. Davidson and E. R. Amick, Jr.: AIChE J., 2 (1956), 1099.

4) T. Tadaki: Tetsu-to-Hagané, 3 (1959), 348.

5) M. Sano and K. Mori: Tetsu-to-Hagané, 60 (1974), 348.

6) M. Sano, K. Mori and T. Sato: Tetsu-to-Hagané, 63 (1977), 2308.

7) S. Asai, T. Okamoto and H. Ji-Cheng: ISIJ Int., 23 (1983), 43.

8) G. G. K. Murthy, S. P. Mehrotra and A. Ghosh: Metall. Trans., 19B (1988), 839.

9) S. Inada and T. Watanabe: Tetsu-to-Hagané, 62 (1976), 807.

10) R. J. Fruehan and L. J. Martonik: Proc. of Third Int. Iron and Steel Cong., April 16-20, (1978), Chicago, 229.

11) Y. Kato, T. Fujii, T. Sakuratani and Y. Kakinama: Tetsuto-Hagané, 69 (1983), 839.

12) M. Iguchi, T. Chihara, T. Kuranaga, H. Ueda, S. Kodani and Z. Morita: Tetsu-to-Hagané, 80 (1994), 8.

13) K. Sakagushi and K. Ito: ISIJ Int., 35 (1995), 1348.

14) C. G. Mair: US Bur. Mines Bull., (1927), 260.

15) T. Tadaki and S. Maeda: Kagaku-Kougaku, 27 (1963), 147.

16) J. R. Grace: Trans. Inst. Chem. Eng., 51 (1973), 116.

17) K. Mori and M. Sano: ISIJ Int., 23 (1983), 169. 